\title{
Expansão dos cursos de graduação em Enfermagem: estudo no Piauí
}

\author{
Expansion of undergraduate Nursing courses: study in Piauí \\ Expansión de los cursos de graduación en Enfermería: estudio en Piauí
}

Maria Eliane Martins Oliveira da Rocha', Benevina Maria Vilar Teixeira Nunes"

'Universidade Estadual do Piauí, Faculdade de Ciências Médicas, Curso de Enfermagem. Teresina-PI, Brasil.

"Universidade Federal do Piauí, Departamento de Enfermagem,

Programa de Pós-Graduação Mestrado em Enfermagem. Teresina-Pl, Brasil.

\author{
Submissão: 20-03-2012 Aprovação: 21-05-2013
}

\section{RESUMO}

Estudo de natureza descritiva, exploratória e retrospectiva, com abordagem quantitativa, que teve como objetivo avaliar a expansão dos cursos de graduação em Enfermagem no Estado do Piauí no período de 1973 a 2008. Pesquisou-se, auxiliado por um formulário, todas as dez instituições de ensino superior existentes, neste período, no Piauí. Os resultados apontam para uma expansão dos cursos de enfermagem nos últimos 10 anos, sendo o crescimento no período de 1973 a 2008 na ordem de $1.300 \%$. Verificou-se um total de 2.949 enfermeiros graduados revelando uma relação per capita para o Piauí de 0,93 enfermeiros/1.000 habitantes. A partir dos dados do estudo constata-se o potencial do Estado na formação de enfermeiros, com crescimento de cursos e vagas. Assim, sublevo reflexão por parte das instituições e órgãos de classe quanto à relação mercado de trabalho e demanda de graduados, qualidade dos cursos e controle de vagas ofertadas.

Descritores: Educação Superior; Educação em Enfermagem; Enfermagem.

\begin{abstract}
A study of descriptive, exploratory and retrospective study with a quantitative approach is to evaluate the expansion of graduate programs in nursing in the state of Piauí in the period 1973 to 2008. It was researched, aided by a form, all ten institutions of higher education in this period, in Piauí. The results pointed to an expansion of nursing programs in the last 10 years, growth in the period 1973 to 2008 in the order of $1.300 \%$. There was a total of 2,949 licensed nurses per capita showing a relation for Piaui of 0.93 nurse/1.000 inhabitants. From the data of the study there is the potential of Piauí in training nurses, with growth of courses and places. Thus, stirs up to reflection on the part of institutions and professional bodies as to the relative labor market and demand for graduates, quality control and course vacancies offered.
\end{abstract}

Key words: Higher Education; Education in Nursing; Nursing.

\section{RESUMEN}

Un estudio de un estudio descriptivo, exploratorio y retrospectivo, con un enfoque cuantitativo para evaluar la expansión de los programas de posgrado en enfermería en el Estado de Piauí, en el período 1973 a 2008. Fue investigado, con la ayuda de un formulario, las diez instituciones de educación superior en este período, en Piauí. Los resultados apuntan a una expansión de los programas de enfermería en los últimos 10 años, el crecimiento en el período 1973 a 2008 en el orden de 1,300\%. Hubo un total de 2.949 enfermeras con licencia per cápita muestran una relación de 0,93 para Piauí enfermera/1.000 habitantes. A partir de los datos del estudio existe la posibilidad de Piauí, en la formación de enfermeras, con un crecimiento de los cursos y los lugares. Por lo tanto, se mueve a la reflexión por parte de las instituciones y organismos profesionales como al mercado de trabajo relativo y demanda de graduados, control de calidad y de las vacantes que se ofrecen los cursos.

Palabras clave: Educación Superior; Educación en Enfermería; Enfermería. 


\section{INTRODUÇÃO}

O presente estudo tem como objeto a configuração dos cursos de graduação em enfermagem no Piauí (PI), no período de 1973 a 2008. Considerou-se como ponto de partida para ampliação dos cursos de enfermagem no Brasil a Reforma Universitária ocorrida a partir da Lei 5540/68, que incrementou o movimento de inserção da carreira das enfermeiras na universidade e impulsionou a criação de novas universidades, aumentando o número de vagas e, conseqüentemente, favoreceram a integração dos cursos existentes e a criação de novos cursos de enfermagem já integrados às universidades ${ }^{(1-2)}$.

Vale ressaltar que não obstante a esse aumento no ensino superior, no inicio da década de 1970 o Ministério de Educação e Cultura (MEC) registrava a enfermagem, como a área do ensino superior que menos havia crescido entre os anos de 1953 a 1973. Além disso, as recomendações do Plano Decenal de Saúde para as Américas, realizado em 1972, estimavam um número de 4,5 enfermeiros por 10.000 habitantes e nessa perspectiva o Brasil apresentava déficit de enfermeiros para atender as necessidades da população ${ }^{(3)}$.

Dessa maneira, em 1975, o Departamento de Assuntos Acadêmicos do MEC (DAU/MEC) ficou responsável pela expansão de novos cursos na área da saúde dentro das universidades públicas federais. Com o trabalho desenvolvido por esse órgão ocorreu novamente a expansão dos cursos de enfermagem no Brasil, sendo que de 1966 a 1970 foram criados cinco cursos, de 1971 a 197516 cursos e de 1976 a 198034 cursos. Ainda de 1981 a 198515 cursos e de 1986 a 1993 mais doze cursos foram criados $^{(4)}$.

A partir da década de 1980, o contexto da evolução dos cursos de enfermagem no Brasil, vem se modificando em virtude da retração do ensino público e avanço do ensino privado, por razões do aprofundamento das dificuldades do quadro econômico nacional, que redefiniu a política educacional do País, especialmente do ensino superior.

Nesse sentido, a aprovação da Lei de Diretrizes e Bases da Educação (LDB), Lei $n^{\circ}$ 9.394/1996, regulamentada pelo Decreto $n^{\circ}$ 2306/97, no Art. 45 menciona que: A educação superior deverá ser ministrada em Instituições de Ensino Superior - IES, públicas ou privadas, com variados graus de abrangência ou especialização( ${ }^{(5)}$. Ressalta-se que para a ampliação do ensino superior foi a publicada a Lei $n^{\circ}$ 9.870/99 que ratificou a possibilidade das instituições educacionais privadas operarem com fins lucrativos ${ }^{(6)}$.

Assim, esses instrumentos legais determinaram uma política educacional que modificou a hegemonia do ensino superior público e gratuito, até então dominante no país, para o ensino superior privado, com expressiva disputa do mercado educacional.

Dessa forma, as Instituições de ensino superior privadas no Brasil passaram de 711 em 1996, para 1.789 em 2004, compreendendo um crescimento de $151,6 \%$, em contrapartida, no mesmo período as universidades públicas passaram de 136 para 169 instituições. Paralelamente, o quantitativo geral de cursos dessas instituições privadas era de 3.666 cursos em 1996, passando para 12.282 cursos em 2004, o que representou um percentual de $237,8 \%$ de crescimento no período ${ }^{(7)}$.
Convém mencionar que o ensino de graduação em enfermagem tem sua expansão relacionada com o próprio crescimento da educação superior no Brasil, principalmente no setor privado, como também com o aumento de vagas no mercado de trabalho para os enfermeiros, por força da abertura de programas assistenciais do Governo e a implantação do Sistema Único de Saúde (SUS), que com suas estratégias de ação oportunizaram oferta de vagas no mercado de trabalho para os profissionais da área, em especial para os enfermeiros que fazem parte da equipe mínima da Estratégia Saúde da Família (ESF) determinada pelo Ministério da Saúde ${ }^{(8-9)}$.

Com a implantação do SUS a partir de 1990, o trabalho do enfermeiro ganhou autonomia profissional, no que se refere à gestão dos serviços de saúde e o atendimento clínico e esse fato atraiu um número crescente de interessados na área, contribuindo para a criação de novos cursos em várias regiões do país.

Neste contexto, é relevante destacar a evolução do crescimento do número de cursos de enfermagem no Brasil, que em 2004 era de 415 cursos e em 2008 já somava $679 \operatorname{cursos}^{(7)}$. Assim, o curso de enfermagem até então está na lista dos que mais se expandiram no período, sendo o de maior quantidade entre os cursos da área de saúde e na maioria das IES se constatam também a oferta de vagas em número superior.

Acredita-se que esse problema merece uma reflexão, pois se entende que o desequilíbrio de profissionais no mercado de trabalho gere desemprego, desvalorização profissional, baixo salários, repercussões na qualidade do ensino, na vida dos futuros enfermeiros, da equipe de saúde e da população.

Nessa perspectiva, o cenário internacional aponta uma série de desafios no que se refere às questões de Recursos Humanos ( $\mathrm{RH}$ ) sendo que alguns se acumulam ao longo dos anos, com destaque para a baixa remuneração e motivação das equipes de saúde, para a iniqüidade distributiva da força de trabalho, e para o desempenho e insatisfação dos profissionais ${ }^{(4)}$.

Dessa forma, entende-se que a abertura de vagas em localidades sem estrutura física, profissionais com qualificação adequada e sem demanda para manter um curso da área de saúde, seja um problema de importância para a categoria dos enfermeiros. Essas situações permitiram reflexões acerca do contexto local (no Estado do Piauí), pois se ficava tomado de um sentimento de impotência diante de pressões políticas por abertura de cursos de graduação em enfermagem em cidades sem estrutura adequada para um curso de saúde.

Diante do problema é relevante discutir sobre os reflexos da expansão dos cursos de enfermagem para essa categoria profissional, pois o crescimento dos cursos é inevitável, todavia é necessário que esse processo ocorra de forma organizada, gerando avanços para a categoria dos enfermeiros. Dessa maneira, objetivou-se avaliar a expansão dos cursos de graduação em Enfermagem no Estado do Piauí no período de 1973 a 2008.

\section{METODOLOGIA}

Trata-se de um estudo de natureza descritiva, exploratório, retrospectivo, de abordagem quantitativa. A pesquisa foi 
realizada em $100 \%$ das IES existentes no estado do Piauí, com cursos de graduação em enfermagem funcionando entre os anos de 1973 e 2008. Pesquisaram-se dez IES, que reúnem ao todo 14 cursos de Enfermagem localizados na capital Teresina e nas cidades de Parnaíba, Floriano e Picos, que se situam no interior do Estado.

Os sujeitos respondentes do estudo foram profissionais que exerciam suas atividades junto às IES e cursos de enfermagem designados para disponibilizar documentos e informações sobre os dados solicitados. Na sua maioria eram coordenadores dos cursos, porém em alguns casos foi necessária a coleta de dados com docentes que conheciam melhor a realidade do curso e também com profissionais de outros setores da IES, na maioria dos casos trabalhou-se com mais de um sujeito.

A coleta de dados ocorreu no período de julho a novembro de 2009. Inicialmente, procederam-se a visitas a cada instituição, com objetivo de solicitar as autorizações para realizar o estudo, sendo protocolada cópia do projeto em cada uma das IES. Com a autorização das IES para realização da pesquisa encaminhou-se o projeto ao Comitê de Ética da UFPI e após parecer favorável (CAA No 0066.0.045.000.09) do referido comitê deu-se inicio o estudo.

Utilizou-se a técnica de aplicação do formulário que foi preenchido a partir de fontes orais e de fontes documentais. A aplicação dos formulários se deu através da entrevista que foi realizada pelas pesquisadoras, que permaneceram no local para esclarecimentos e preenchimento dos dados. Outro momento também utilizado como forma de inquirir os dados solicitados no formulário foi a visita aos Departamentos Acadêmicos (DAA) das duas universidades públicas e também aos setores responsáveis pelos vestibulares de IES públicas e privadas, pois só nestes setores foi possível adquirir dados sobre a oferta de vagas e número de graduados nos cursos de enfermagem do período estudado.

O formulário utilizado como fonte de coleta de dados foi dividido em partes, composto por questões estruturadas, contendo perguntas pré-codificadas, semi-abertas e abertas e que tiveram suas indagações elaboradas com base nas variáveis do estudo. As variáveis estudadas foram: Número de cursos de enfermagem existentes nas IES do Piauí no período de 1973 a 2008; número de cursos de enfermagem das IES públicas e privadas; número de vagas anuais ofertadas nos vestibulares de 1973 a 2008 nos cursos de enfermagem; número de alunos graduados por ano no período de 1973 a 2008; e distribuição geoeducacional dos cursos de enfermagem no Estado.

Os dados foram consolidados em um instrumento construído pelos autores que permitiu o exame das informações dos cursos em conjunto, favorecendo a organização, análise e interpretação dos resultados. Estes dados tiveram um tratamento estatístico mediante frequência simples e percentual. A planilha eletrônica Microsoft Office Excel 2007 foi utilizada para a construção das tabelas, quadros e gráficos.

\section{RESULTADOS E DISCUSSÃO}

Dentre as IES públicas estudadas, uma é federal e outra estadual e oferecem juntos 06 cursos de enfermagem somados os da capital e do interior do Estado; e oito IES são privadas e ofertam 08 cursos de enfermagem. A evolução dos cursos no recorte temporal do estudo mostra que houve a criação e também extinção de cursos de enfermagem.

Durante 25 (vinte e cinco) anos o curso de enfermagem da Universidade Federal do Piauí (UFPI) permaneceu como o único do Estado e somente a partir de 1998 foram criados novos cursos de graduação em enfermagem, com a abertura de cursos da área de saúde pela Universidade Estadual do Piauí (UESPI), tanto na capital Teresina como nos municípios do interior do Estado.

O gráfico 1 evidencia um crescimento de um para dois cursos de enfermagem no período de 1973 a 1998, no Estado do Piauí. Já de 1999 a 2003 houve um crescimento de três para 11 cursos, ou seja, uma expansão na ordem de $267 \%$ nestes cinco anos. No ano de 2004, outros três novos cursos foram abertos na capital Teresina, somando um total de 14 cursos, com um pico de crescimento de 2002 até 2004. Todavia, ao tempo em que novos cursos são instituídos, outros são fechados como mostrado no Gráfico 1. Assim, seis cursos na UESPI foram fechados, no ano de 2004 no interior do Estado, ocorrendo uma diminuição no quantitativo geral de cursos, resultando em oito cursos. Em 2005, nenhum curso foi instituído. No período de 2006 a 2008 seis novos cursos de enfermagem foram criados, sendo que a média de crescimento

Gráfico 1 - Evolução dos Cursos de Enfermagem no estado do Piauí durante o período de 1973 a 2008. Teresina-PI, 2010.

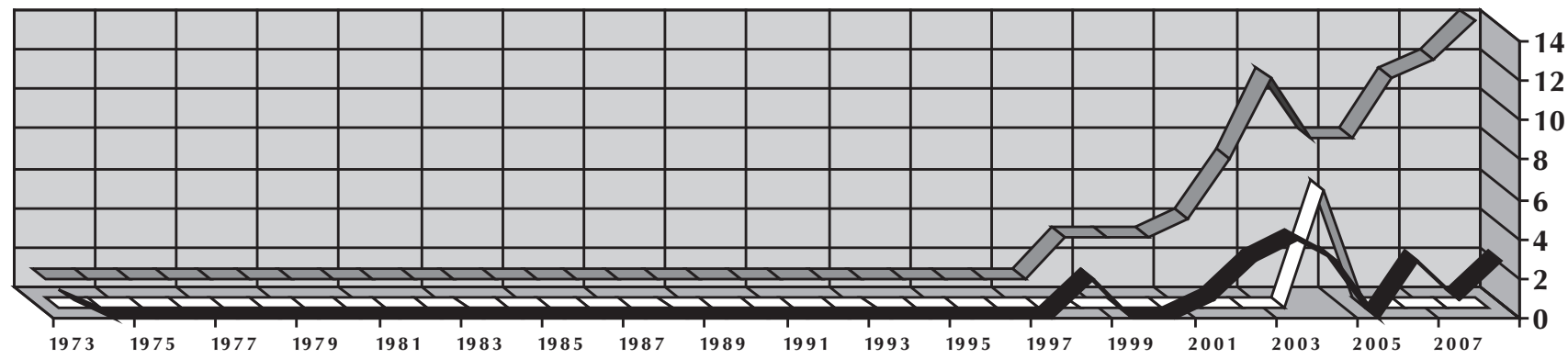


nesse período foi de dois cursos por ano, totalizando 14 cursos em 2008.

Dessa maneira, observa-se que a expansão dos cursos de enfermagem no Piauí acelera-se na década de 2000 a 2010 e o crescimento geral no período de 1973 a 2008 foi de $1.300 \%$ (1 para 14 cursos), isso levando em consideração que seis cursos foram extintos no interior do estado.

Esse crescimento de cursos de enfermagem no estado do Piauí é reflexo do contexto vivido pela educação, em geral, da enfermagem brasileira. Os aspectos que influenciaram a expansão dos cursos de enfermagem no Brasil, a partir da década de 1970, têm determinantes históricos, como o Plano Decenal de Saúde para as Américas, ocorrido em 1972, cuja meta foi de aumentar o quantitativo de enfermeiros no país. Esse fato influenciou a ampliação do número de vagas e a abertura de novas escolas de enfermagem. Também contribuíram para essa expansão o Programa Crédito Educativo (CREDUC), em 1976, no qual o governo subsidiava o ensino do aluno em instituições públicas e privadas e este, depois de formado, assumia o compromisso de devolvê-lo(10).

Seguidamente, contribuíram ainda para a expansão dos cursos a Constituição Federal de 1988, que manteve o princípio do ensino livre para a iniciativa privada; as políticas de educação desenvolvidas nos governos de Fernando Collor de Mello (1990-1992), Itamar Franco (1992-1994) e de Fernando Henrique Cardoso (1995-2002) e a criação da Lei de Diretrizes e Bases da Educação Nacional de 1996, que traz também mudanças, determinantes da ampliação e reforma do ensino superior brasileiro. Em decorrência das políticas adotadas pelos governos, observa-se um aumento do número de escolas de enfermagem criadas no Brasil. No período entre 1970 e 1999 foram criadas no país 166 escolas, sendo 70\% privadas e $30 \%$ públicas $^{(11)}$.

Dessa maneira, o crescimento dos cursos de enfermagem no Estado do Piauí está em consonância com o que ocorreu no país e, principalmente, com as transformações determinadas pela LDB de 1996. Segundo dados do Censo da Educação Superior de 2006, registraram-se a existência de 22.101 cursos de graduação presenciais no Brasil; em 1996 existiam 6.644. Portanto, essas estatísticas indicam um crescimento elevado dos cursos, cerca de 232,6\%, no período 1996-2006 ${ }^{(11)}$.

Ainda, no contexto da expansão quantitativa dos cursos, a Sinopse Estatística da Educação Superior, traz o curso de enfermagem como o mais ofertado dentre os cursos da área de saúde, totalizando 679 cursos; seguido de fisioterapia, com 476; psicologia, com 416; farmácia, com 353; educação física, com 335; nutrição, 309; odontologia, com 197; e medicina, com $177^{(12)}$. Essa expansão pode ser verificada de forma mais acentuada no período que compreende os anos de 2001 a 2008 em que os cursos de enfermagem passam de 215 para $679^{(13)}$. Observa-se assim, que o curso de enfermagem no Brasil apresenta percentual de crescimento superior aos demais cursos da área de saúde analisados.

Outro item importante estudado refere-se à cronologia em que surgiram os cursos nas IES públicas e privadas. E neste contexto, observa-se que houve uma expansão a partir dos anos 2000 de cursos e que isso refletiu num aumento no quantitativo de vagas no âmbito público e principalmente no privado, como é retratado no gráfico 2 e tabela 01 .

O primeiro curso de graduação em enfermagem criado no Estado do Piauí foi o da Universidade Federal do Piauí (UFPI), no ano de 1973 na cidade de Teresina. O primeiro vestibular aconteceu em 1973, com oferta de vinte vagas e a autorização para seu funcionamento ocorreu em 1974, por meio do ato da Reitoria n. ${ }^{\circ}$ 198/74, sendo reconhecido, em 1978, pelo Ministério da Educação, por meio do Parecer 2.137/1978 do Conselho Federal de Educação(1). Observou-se nesse período (1973 a 2008) que o crescimento dos cursos de enfermagem na esfera pública federal se deu lentamente, pois foram 35 anos, da abertura do primeiro curso de enfermagem em 1973 na UFPI até a implantação do segundo curso em 2006, no interior do Estado, na cidade de Picos.

Gráfico 2 - Criação dos Cursos de Enfermagem entre IES públicas e privadas no estado do Piauí, período de 1973 a 2008. Teresina-PI, 2010.

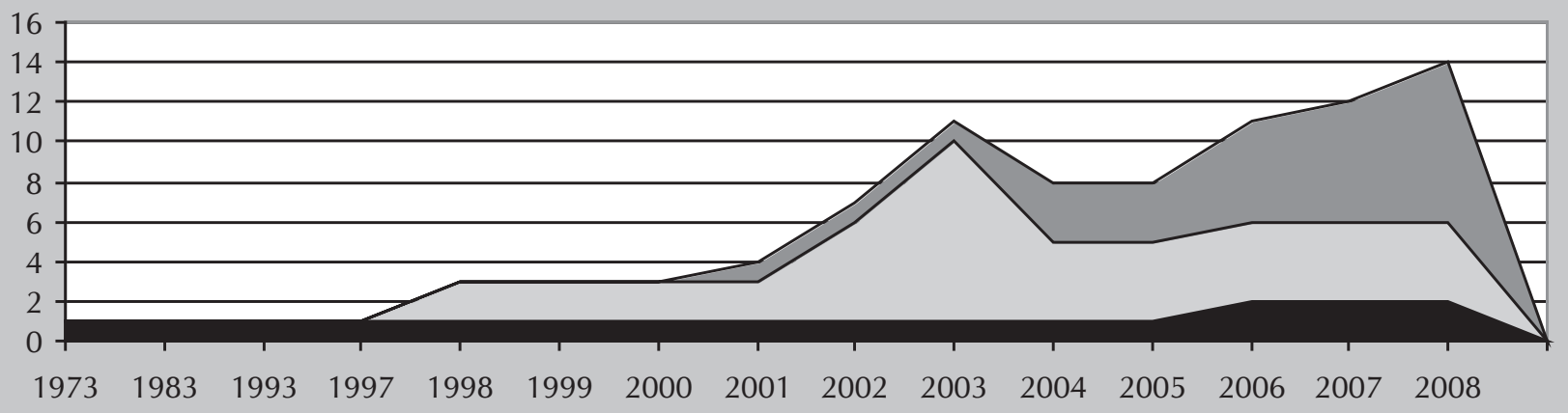

Cursos rede pública federal $\quad \square$ Cursos rede pública estadual $\quad \square$ Cursos rede privada 
Já o Curso de Enfermagem, no âmbito público estadual, foi o primeiro da área de saúde criado no interior do Estado e o segundo no contexto geoeducacional estadual. Sendo que, em 1998, a UESPI criou dois cursos de enfermagem nas cidades de Parnaíba e Floriano. No ano de 2002 três cursos foram abertos nas cidades de Picos, Água Branca e Barras. No ano de 2003 criaram-se mais quatro novos cursos nas cidades de Campo Maior, Piracuruca, Corrente e Bom Jesus, totalizando nove cursos abertos na IES Estadual nesse período.

Porém, no inicio do ano de 2004, por dificuldades estruturais e organizacionais, seis dos nove cursos existentes são fechados e seus alunos foram transferidos através da Resolução CONSUN nº. 014/04 (05/03/2004), que autorizou o remanejamento de alunos do Curso de Enfermagem da seguinte forma: Alunos dos Campi de Bom Jesus e Corrente para Floriano, Piracuruca para Parnaíba, Água Branca ( $3^{\circ}$ e $5^{\circ}$ blocos), Barras ( $5^{\circ}$ bloco), Campo Maior ( $2^{\circ}$ e $3^{\circ}$ blocos) para Teresina dando origem ao curso junto a Faculdade de Ciências Médicas - FACIME/UESPI, onde já funcionava o curso de Medicina (1999), Fisioterapia e Psicologia. Porém, o primeiro vestibular para o curso de Enfermagem em Teresina da Universidade Estadual do Piauí, só ocorreu de 2007/2008 após conclusão do curso pelas turmas transferidas ${ }^{(14)}$. Após essa mudança no contexto dos cursos, a Universidade Estadual se mantém com quatro cursos de enfermagem.

A expansão da Universidade Estadual do Piauí (UESPI) pautou-se na diversificação da oferta e interiorização dos cursos. Em 1991, abriu vagas em vários Polos no interior do Estado, inseriu cursos sequenciais e presenciais e criou novos cursos em anos posteriores em varias cidades do Es$\operatorname{tado}^{(5)}$. Foi um processo de aceleração que coloca a UESPI, em 2003, entre as dez maiores universidades do Brasil e seu ápice se deu de 1996 a 2004, com crescimento de 1.137\%, superando a expansão da rede privada de ensino superior nesse período.

Quanto ao crescimento dos cursos de enfermagem na organização administrativa privada, se inicia no ano de 2001, como explicitado no gráfico 2, quando surge o primeiro curso da rede privada de ensino superior na Faculdade de Saúde, Ciências Humanas e Tecnológicas do Piauí (NOVAFAPI). Em 2004 são criados mais dois cursos, um situado na capital Teresina na Faculdade Integral Diferencial (FACID) e outro na cidade de Floriano, na Faculdade de Ensino Superior de Floriano (FAESF), que foi o primeiro curso privado em municípios do interior do Estado.

Em 2005, nenhum curso foi criado, em 2006 mais dois cursos são instituídos nas faculdades: Faculdade Santo Agostinho (FSA) e Faculdade de Ciências Humanas e Jurídicas de Teresina (FACULDADE CEUT). Em 2007 cria-se um curso na Faculdade
Certo (FACE) que posteriormente passa a Faculdade ALIANÇA; e finalmente no ano de 2008 dois novos cursos são implantados: uma na Faculdade São Gabriel (FSG/UNESC) e outro na Associação de Ensino Superior do Piauí (AESPI). Assim, os cursos de enfermagem nas instituições privadas somam, até o primeiro semestre de 2008, oito cursos e seu crescimento se dá em ordem superior ao do setor público, pois em oito anos, ou seja, de 2001 a 2008 os cursos de enfermagem na organização administrativa privada, aumentam na ordem de $700 \%$.

A partir da década de 1990 existiu um aquecimento no sistema educativo para enfermagem, com expressiva expansão de cursos e de vagas para enfermagem nessa década e que se intensifica nos anos 2000, com expressivo crescimento no setor privado com proporções elevadas. E essa expansão dos cursos no Piauí se dá não só na capital Teresina, mas também em cidades do interior do Estado como retrata o gráfico 3.

Ao analisar a distribuição geoeducacional de cursos de enfermagem no âmbito dos municípios do Estado do Piauí, observa-se uma concentração de cursos na capital Teresina, o que não difere de outros Estados da federação, onde existe uma concentração de cursos nas cidades com maior desenvolvimento populacional e econômico, principalmente nas capitais dos Estados.

O Estado do Piauí possuía até o ano de 2008, 14 cursos de enfermagem, sendo nove cursos (64\%) concentrados na capital Teresina e cinco (36\%) situados em três cidades do interior do Estado. Na análise da distribuição geoeducacional dos cursos e sua natureza jurídica (privada ou pública), observa-se que seis são público e concentram-se: dois na capital Teresina e quatro no interior do Estado, nas cidades de Parnaíba, Floriano e Picos. Quanto aos da rede privada de ensino são oito e concentram-se: sete na capital Teresina, e um na cidade de Floriano.

Do ponto de vista do número de vagas ofertadas, observou-se que até os anos de 1900 eram restritas ao setor público e só a partir dos anos 2000 é que as IES privadas abrem cursos e vagas para o curso de enfermagem no Estado. A tabela 1 retrata esse quantitativo de vagas ofertada por cursos nas esferas pública e privada, o número de graduados e a oferta no ano de 2008 .

Gráfico 3 - Cursos de Enfermagem quanto à natureza jurídica pública ou privada e situação geoeducacional, no período de período de 1973 a 2008. Teresina, Piauí, 2010.

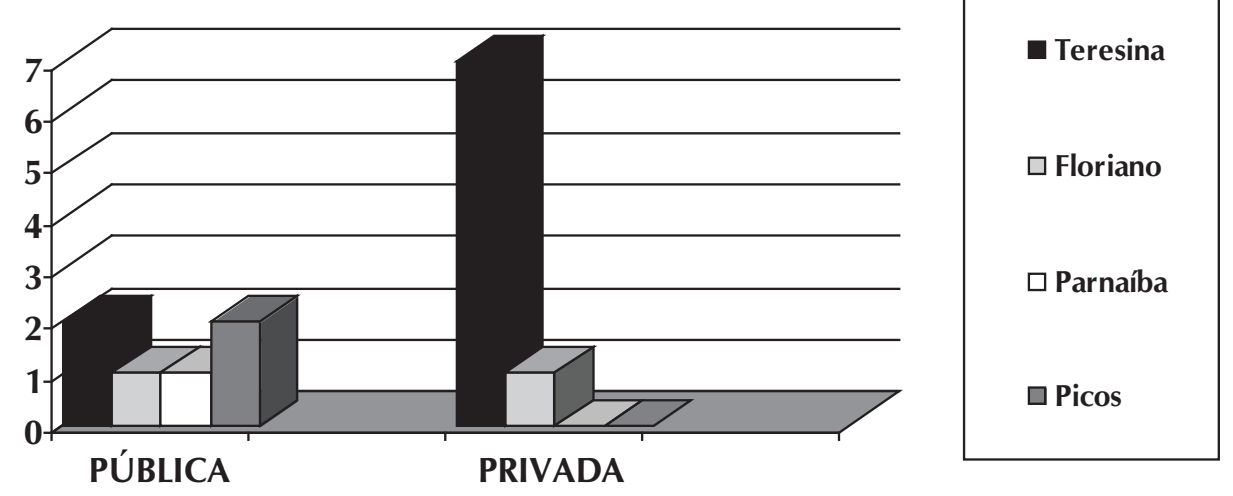


Tabela 1 - Cursos de Enfermagem quanto ao número de vagas ofertadas, quantitativo de graduados nas Instituições de Ensino Superiores Públicas e Privadas de 1973 a 2008 e oferta de vagas no vestibular de 2008/2009. Teresina - Piauí, 2010.

\begin{tabular}{|c|c|c|c|c|c|}
\hline \multirow[b]{2}{*}{ CURSO / IES } & \multicolumn{3}{|c|}{ PERÍODO DE 1973 A 2008} & \multirow[b]{2}{*}{ Graduados } & \multirow{2}{*}{$\begin{array}{c}\text { Oferta anual Ves- } \\
\text { tibular } \\
2008 / 09\end{array}$} \\
\hline & $\begin{array}{l}\text { Vagas } \\
\text { Ofertadas }\end{array}$ & Graduados & Vagas Ofertadas & & \\
\hline & Públicas & & Privadas & & \\
\hline 01 & - & & 1.275 & 660 & 200 \\
\hline 02 & 225 & 162 & - & & 25 \\
\hline 03 & 360 & 223 & - & & 25 \\
\hline 04 & 405 & 376 & - & & 25 \\
\hline 05 & 180 & 98 & - & & 25 \\
\hline 06 & 1.860 & 1.060 & - & & 80 \\
\hline 07 & 250 & 00 & - & & 100 \\
\hline 08 & - & - & 250 & 00 & 100 \\
\hline 09 & - & - & 500 & 134 & 100 \\
\hline 10 & - & - & 600 & 00 & 200 \\
\hline 11 & - & - & 200 & 00 & 100 \\
\hline 12 & - & - & 100 & 00 & 100 \\
\hline 13 & & - & 100 & 00 & 100 \\
\hline 14 & - & - & 500 & 236 & 100 \\
\hline Total & 3.280 & 1.919 & 3.525 & 1.030 & 1.280 \\
\hline
\end{tabular}

No estudo observou-se que foram ofertadas 6.805 vagas para enfermagem no Piauí, sendo que em 35 anos, de 1973 a 2008, foram ofertadas $3.280(48,2 \%)$ vagas nos cursos de enfermagem das IES públicas, enquanto que na rede privada de 2001 a 2008 foram ofertadas 3.525 (51,8\%) vagas, quantidade superior ao ofertado no setor público de ensino superior e num período de tempo inferior.

Já o número de graduados nas IES estudadas revelou que, $1.919(65 \%)$ dos enfermeiros foram graduados nas duas universidades públicas do Estado e, 1.030 (35\%) foram graduados em faculdades privadas, dando um total de graduados em enfermagem no Estado do Piauí, no período de 1973 a 2008, de 2.949 profissionais. Os dados da rede pública refere-se a 32 anos, ou seja, do período de 1977 (quando primeira turma é graduada) a 2008, e os da rede privada referem-se a quatro anos, período de 2004 (ano formatura da primeira turma) a 2008, e já representam aproximadamente um terço dos graduados no Estado do Piauí.

Outro item levantado refere-se aos graduados oriundos de cursos situados em cidades do interior do Estado do Piauí, que foram responsáveis pela formação de 933 profissionais, sendo 236 em IES privadas e 697 em IES públicas. Na capital Teresina se graduaram 2.016 enfermeiros. Como o somatório de enfermeiros graduados no Estado do Piauí nos 14 cursos pesquisados, no recorte temporal citado, é de 2.949 profissionais para a população do Estado que era de 3.145.325, temos uma relação per capita do Estado de 0,93 enfermeiros/1.000 habitantes. Já a capital Teresina que tinha 2.016 profissionais graduados para uma população de 793.915 habitantes, a per capita é de 2,54 enfermeiros/1.000 habitantes.

Estes dados trazem uma realidade importante para o contexto da enfermagem piauiense, pois os resultados mostram que o Piauí tem índices maiores que a média brasileira que tem relação per capita de 0,6 enfermeiros/ 1.000 habitantes. Já Teresina está próxima aos países da Europa que varia de 3 a 5 enfermeiros/1.000 habitantes ${ }^{(1)}$. Desta forma o Piauí, e principalmente a capital Teresina, tem uma relação per capita em níveis de países de $1^{\circ}$ mundo, porém com mercado de trabalho bem aquém destes países, o que mais uma vez nos remete a preocupação com a quantidade de cursos e qualidade do ensino. Diante dos dados apresentados pode-se afirmar que não há necessidade da criação de cursos e vagas no Piauí, como continua acontecendo.

Observa-se que embora a oferta de vagas no período seja maior na rede privada, ainda a maioria dos profissionais graduados no Estado é oriunda de IES públicas. No entanto, em 2001, um único curso da rede privada ofertou 100 vagas anuais; já em 2008 a rede privada conta com oito cursos e oferta 1.000 (mil) vagas anuais. O que reflete um aumento na ordem de $900 \%$ no quantitativo de vagas ofertadas/ano no setor privado de ensino de graduação em enfermagem no Piauí nestes oito anos (20012008). Já na rede pública, em 1973, o curso da UFPI iniciou com oferta de 20 vagas anuais, e em 2008, após 35 anos, a oferta em seis cursos da rede pública (federal e estadual) é de 280 vagas anuais, um acrescimento de $1.300 \%$ no número de vagas ofertadas/ano, porém, em quantitativo muito inferior aos da rede privada no mesmo ano que é de 1.000 vagas.

O Censo da Educação Superior (CES) de 2008 revela um aumento, de modo geral, do número de vagas oferecidas, todavia o mesmo não foi acompanhado por um crescimento proporcional no número de ingressos, resultando em vagas ociosas no âmbito das IES sejam nas categorias administrativas públicas ou privadas ${ }^{(15)}$. 
Gráfico 4 - Distribuição das vagas nos Cursos de Enfermagem na rede Pública Federal e Estadual e Privada, no período de 1973 a 2008. Teresina, Piauí, 2010.

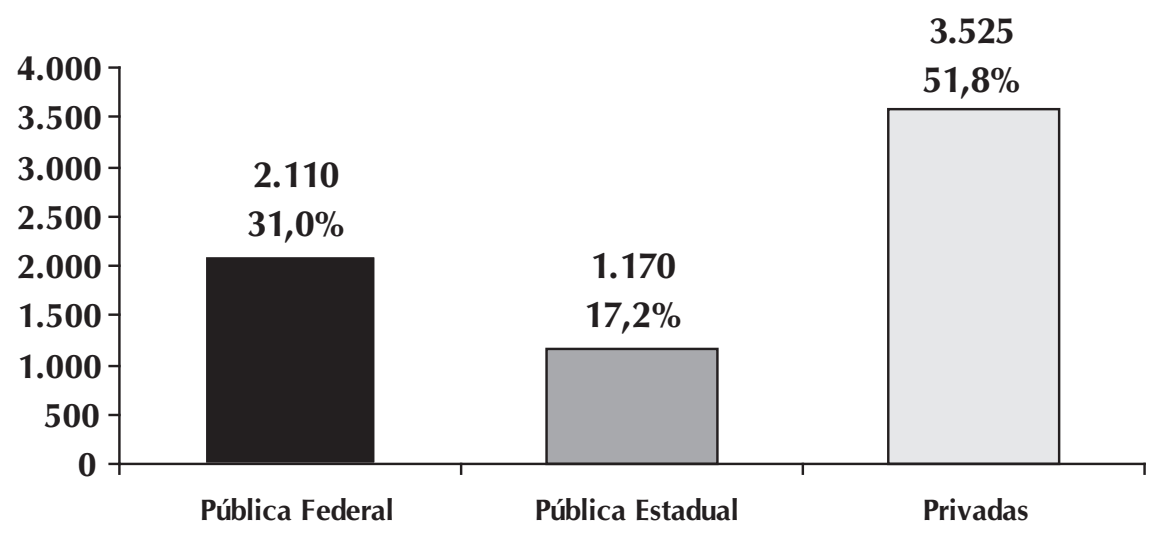

Observa-se a oferta de vagas no curso de Enfermagem do setor educacional superior privado já representa 51,8\% (2001-2008) do total de vagas ofertado. Enquanto que na rede pública (federal e estadual) a oferta foi de $48,2 \%$ do total de vagas do período, sendo 31,0\% (2.110 vagas) ofertada pela Universidade Federal e 17,2\% (1.170 vagas) pela Universidade Estadual. A partir do ano de 1996 o Piauí registrou uma expansão do ensino superior na ordem de $333 \%$, chegando em 2004 com 26 instituições de ensino superior distribuídas em todo o Estado(5). Desta forma, o crescimento dos cursos de enfermagem no Piauí acelerou-se na década de 2000 em razão também do aumento dos cursos superiores no Estado, principalmente na rede privada de ensino.

Reportando-se ao ano de 2008 e aos dados apresentados na tabela 1, quanto à oferta de vagas no Estado de Piauí, temos um panorama de distribuição de vagas centrado no setor privado, que teve uma oferta, nesse ano, de 1.025 vagas (78\%), enquanto que o setor público federal e estadual teve $280(22 \%)$ de oferta. Em consequência disso pode-se dizer as IES privadas no futuro bem próximo, serão responsáveis pela formação da maioria dos enfermeiros do Estado.

O estudo também mostrou que, em quase 30 anos, de 1973 a 1999, foram ofertadas 1.440 vagas eminentemente na rede pública estadual e federal; de 2000 a 2008, ofertou-se mais 1.840 vagas. Enquanto que, na rede privada, de 2000 a 2008 foram ofertadas 3.525 vagas. É notório, portanto o crescimento das vagas no ensino privado, mas, também, houve um tímido aumento da oferta de vagas no ensino público para enfermagem no período de 2000 a 2008.

\section{CONCLUSÃO}

O estudo evidenciou que a expansão dos cursos de enfermagem no estado do Piauí se deu principalmente a partir dos anos 2000 e com um quantitativo superior ao crescimento registrado nos 25 anos anteriores.

A expansão dos cursos quanto à categoria administrativa pública e privada se dá de forma desproporcional, pois na rede privada em oito anos, ou seja, de 2001 a 2008, o crescimento é da ordem de $700 \%$, enquanto na categoria pública, de
1973 a 2008 é de um para seis cursos, representando um aumento de 500\%, em 35 anos. Ressaltando que durante esse recorte temporal, seis cursos de enfermagem da rede pública estadual de ensino superior, foram extintos por falta de condições para funcionar e seus discentes transferidos para outros Campi da universidade Estadual.

Quanto à distribuição dos cursos no contexto geoeducacional, $64 \%$ estão concentrados na capital Teresina e 36\% situados em cidades do interior do Estado, o que não difere de outros Estados da federação, onde existe uma concentração de cursos nas cidades com maior desenvolvimento populacional e econômico, principalmente nas capitais dos Estados.

Observou-se que foram ofertadas 6.805 vagas para enfermagem no Estado do Piauí, sendo 3.280 vagas (1973 a 2008) nos cursos de enfermagem das IES públicas, e 3.525 vagas (2000 a 2008) na rede privada. Houve um crescimento expressivo do setor privado, pois a partir de 2001, quando surgem os primeiros cursos de enfermagem em IES privadas, ate o ano de 2008, a oferta de vagas em IES privadas supera a oferta das instituições públicas, em 35 anos.

O estudo mostra, também, que o número de graduados da rede pública em 32 anos (1977 a 2008) é de 1.919 (65\%) enfermeiros, e na rede privada em oito anos (2001 a 2008) é de 1.030 (35\%) enfermeiros, aproximadamente um terço dos graduados do estado do Piauí. O total de enfermeiros graduados no Estado do Piauí, no recorte temporal de 1973-2008 é de 2.949, revelando uma relação per capita do Estado de 0,93 enfermeiros/1.000 habitantes. Quanto a capital Teresina que teve 2.016 enfermeiros (68,4\% do total) a per capita é de 2,54 enfermeiros/1.000 habitantes. A capital Teresina tem uma relação per capita em níveis de países de $1^{\circ}$ mundo, porém com mercado de trabalho bem aquém destes países, o que mais uma vez nos remete a preocupação com a quantidade de cursos e profissionais graduados.

A oferta de vagas no ano de 2008 pelas IES mostra um quantitativo de vagas superior nas instituições privadas e assim, pode-se afirmar que o crescimento e a prevalência das vagas dos cursos de enfermagem no setor privado pode teoricamente determinar o perfil dos futuros profissionais no mercado de trabalho piauiense, pois o quantitativo de vagas ofertado pelos cursos de enfermagem no setor público é de aproximadamente $22 \%$ e do privado de $78 \%$.

Diante dos dados apresentados pode-se dizer que não há mais tanta necessidade de ampliação de cursos e vagas no Piauí, como continua acontecendo, merecendo uma reflexão quanto à relação mercado de trabalho e salários ofertados e demanda de graduados, qualidade dos cursos e número de vagas ofertadas.

Espera-se que resultados quantitativos sirvam como indicador válido para discutir sobre a repercussão para o mercado de trabalho do enfermeiro, diante do contexto de expansão 
quantitativa dos cursos de enfermagem no Piauí e também no Brasil.

Mesmo existindo a necessidade preditiva de enfermeiros no Brasil, no Piauí os dados trazem uma realidade preocupante e estes refletem atualmente em consequências negativas, pois o sistema, os governantes e gestores da saúde não têm respondido ao quantitativo de enfermeiros existentes com bons empregos, bons salários, com carga horária compatível e valorização do profissional. O cenário piauiense de expansão dos cursos de enfermagem no momento merece ser acompanhado, tanto do ponto de vista quantitativo quanto qualitativo, pois de um lado temos um grande número de enfermeiros para o mercado de trabalho, do outro o risco de ter um mercado com profissionais sem qualificação adequada.

O estudo foi acima de tudo um desafio, pois a cada análise dos dados novas inquietações, reflexões, angústias surgem e remetem a responsabilidade docente, formador de opinião e de enfermeiros para um mercado de trabalho desafiador. Desta forma, espera-se que esse trabalho contribua para a construção de uma consciência coletiva de todos os envolvidos no processo educacional, quanto ao seu papel no processo de formação, empregabilidade e responsabilidade social, no cenário estadual e nacional para os enfermeiros.

\section{REFERÊNCIAS}

1. Nunes BMVT, Baptista SS. Os primórdios do ensino de enfermagem moderna no Piauí: lutas e conquistas na universidade (1973-1977). Teresina: EDUFPI; 2004.

2. Baptista SS, Barreira IA. A luta da enfermagem por um espaço na Universidade. Rio de Janeiro: IFRJ; 1997.

3. Paim L. A formação dos enfermeiros no Brasil na década de 70. Rev Bras Enferm 2001;54(2):185-96.

4. Fernandes JD. A privatização do ensino de enfermagem no Brasil: economia da qualidade. Rev Bras Enferm 1994;47(2):144-59.

5. Instituto Nacional de Estudos e Pesquisa. Educação Superior Brasileira: 1991-2004. Brasília, DF: INEP; 2006.

6. Ministério da Educação e Cultura. Censo da Educação Superior 2004. Brasília, DF: O Ministério; 2006.

7. Ministério da Educação e Cultura. Censo da Educação Superior 2008: Dados preliminares. Brasília, DF: O Ministério; 2009.

8. Pierantoni C. As reformas do estado, da saúde e recursos humanos: limites e possibilidades. Ciênc Saúde Coletiva 2001;6(2):341-60.

9. Nunes BMVT, Baptista SS. Os primórdios do ensino de enfermagem moderna no Piauí: lutas e conquistas na universidade (1973-1977). Teresina: EDUFPI; 2004.

10. Barbosa TSC, Baptista SS. Movimento de expansão dos cursos superiores de enfermagem na região centro-oeste do Brasil: uma perspectiva histórica. Rev Eletr Enf 2008;10(4):945-56.

11. Segenreich SCD, Castanheira AM. Expansão, privatização e diferenciação da educação superior no Brasil pós - LDBEN/96: evidências e tendências. Ensaio: Aval Pol Públ Educ 2009; 17(62):55-86.

12. Instituto Nacional de Estudos e Pesquisas Educacionais Anísio Teixeira. Sinopse Estatística da Educação Superior 2008. Brasília, DF: INEP; 2009.

13. Vieira ALC, Garcia ACP, Amâncio Filho A, Pierantoni CR, Ferraz CA, Oliveira ES, et al. Tendências do sistema educativo no Brasil: medicina, enfermagem e odontologia. Observatório de Recursos Humanos em Saúde no Brasil, Estudos e Análises. Ciênc Saúde Coletiva 2003;12(3):26-32.

14. Universidade Estadual do Piauí. Dossiê Enfermagem: reconhecimento do curso. Teresina: Universidade Estadual do Piauí; 2007.

15. Ministério da Educação (Brasil). Resolução nº. 04, de 06 de abril de 2009. Dispõe sobre carga horária mínima e procedimentos relativos à integração e duração dos cursos de graduação em Biomedicina, Ciências Biológicas, Educação Física, Enfermagem, Farmácia, Fisioterapia, Fonoaudiologia, Nutrição e Terapia Ocupacional, bacharelados, na modalidade presencial. Diário Oficial da União 07 abr 2009;Seção 1. 